\title{
A competency framework for the business rescue practitioner profession
}

\begin{abstract}
Author:
Marius Pretorius ${ }^{1}$

Affiliation:

${ }^{1}$ Department of Business

Management, University of

Pretoria, South Africa

Correspondence to:

Marius Pretorius

Email:

marius.pretorius@up.ac.za

\section{Postal address:}

Department of Business

Management, University

of Pretoria, Pretoria 0002,

South Africa

\section{Dates:}

Received: 26 Sept. 2013

Accepted: 24 Apr. 2014

Published: 18 Aug. 2014

How to cite this article:

Pretorius, M., 2014, 'A

competency framework

for the business rescue

practitioner profession', Acto

Commercii 14(2), Art. \#227,

15 pages. http://dx.doi.

org/10.4102/ac.v14i2.227

Note:

Permission was granted by the Southern Africa Business Review to publish this article in part, as it is based on the same methodology used. The specific article is referenced, based on the Best qualitative paper presented at SAIMS 2013, which is available from http://www.brportal. co.za/_literature_163900/ BRP_Competencies_?
\end{abstract}

\section{Copyright:}

(C) 2014. The Authors. Licensee: AOSIS OpenJournals. This work is licensed under the Creative Commons Attribution License.
Orientation: Business Rescue Practitioner (BRP) tasks are complex and involve a wide range of knowledge, tacit skills and experience not accessible to novices.

Research purpose: Competencies required by business rescue practitioners (BRPs) to navigate a distressed venture were investigated. What BRPs actually 'do' during a rescue guided the development of a competency framework to inform future qualification guidelines for BRP education and accreditation.

Motivation for the study: To investigate the research question: 'What are the competencies that underlie the activities of a business rescue practitioner?'.

Research design, approach and method: A modified 'interview to the double' (ITTD) process was used to elicit instructions that a BRP would give to an imaginary 'double'. These instructions were analysed and rated for importance, transferability, knowledge requirement and skills requirement; in conclusion, these instructions were ranked and subjected to a content analysis.

Main findings: Based on the main activities that were derived from the practices and praxis, one assignment and four supra (higher-level) competencies were consequent to the analysis. A BRP able to successfully navigate a distressed venture towards normal operations should demonstrate a high level of competency in sense-making, decision making and integration, achieved through collaboration as the central competency.

Practical implications: Firstly, the study addresses educators' need for a framework of competencies to guide education. Secondly, it paves the way for the Regulator to develop a qualifications framework for accreditation.

Contribution: The findings gave structure to the competencies underlying the activities of a BRP to navigate a rescue. Pre-business and financial acumen appears limited without these competencies containing insight, experience, intuition, heuristics, tacit knowledge, perceptive induction and more.

\section{Introduction}

A Chinese proverb states, 'When fate throws a dagger at you, there are only two ways to catch it - either by the blade or the handle'. Turnaround professionals and business rescue practitioners (BRPs) 'must catch such knives recurrently - almost on a daily basis' (McCann 2009). BRPortal (2012) reported the reputation of competence of BRPs as being a critical scenario driver for the rescue industry. Selecting someone to lead a rescue of a distressed venture (firm or organisation) is therefore an immensely important decision because of the potential consequences the choice may have for creditors, shareholders and employees. Baird and Lorence (2012:21) postulate that within the turnaround industry there are currently no broadly-accepted tools, systems and processes to predict the success of turnaround practitioners. The questions arise: 'What competencies are required for BRPs to catch these knives by the handle every time?'; and 'What is the best way to select individuals for the required competence?'.

At present, proposed selection guidelines for BRPs appear to be aligned with generallydefined competencies of leaders and change agents and can, at best, be described as vague. The Turnaround Management Association's body of knowledge describes the required characteristics of turnaround managers only in general terms, to include strategic, tactical and leadership skills (Turnaround Management Association [TMA] 2009:4-1). There is no reference to unique differentiators for BRPs beyond those associated with entrepreneurs and business managers. Pretorius and Du Preez (2013:184) and Du Preez (2012:74) report that banks (usually the critical creditor) often base their post-commencement financing decisions on who is appointed as the BRP. This holds serious consequences for the industry, as their reasoning and decisions with regard to how competence is assessed are not accessible to anyone outside the bank. 
As the amended Companies Act 71 of 2008 (South Africa 2008; 'the $A c t^{\prime}$ ) has only been in operation since May 2011, the business rescue practitioner is a new phenomenon and this is, as yet, a young profession. BRPs (including turnaround managers) face complex assignments. Generally, BRP selection criteria are described in an unstructured, complex, mostly generic manner. Competency requirements in the Act contain disqualifications rather than qualifications. No formal scientific research exists to direct the qualifications of BRPs to guide the Companies and Intellectual Property Commission (CIPC), who is the appointed Regulator.

Whilst there is a need to advise distressed businesses who want to file for rescue, as well as future applicants who want to be certified on the competence requirements for certification of BRPs, two obvious stakeholders are foremost in driving the need for a framework.

Firstly, educators need competency guidelines regarding the required BRP skills and competencies, as currently these are unclear. Teaching of standard business management competencies is not enough, as businesses in distress require more complex competencies. Midanek (2002:24) refers to these as the knowledge, skills and abilities associated with 'war zone' experiences; yet the particular competencies required remain elusive.

Secondly, the Regulator requires a framework for measuring competence (Lotheringen 2013, pers. comm.). The CIPC as the regulatory authority (in terms of Chapter 6 of the Act) may license 'qualified' persons to act as practitioners after a filing business requests a specific person for the assignment. At this point, the CIPC has no distinct guidelines other than the vague disqualifications from the Act for measurement of competence. This aspect is important, as the rescue industry is only about three years old, following the new legislation since Chapter 6 of the Act, as amended, came into effect on 01 May 2011.

Five key activities (from a longer list of 15), based on practices and praxis describing the tasks for BRPs to execute in rescue, were identified by Pretorius (2013) with regard to directing the competencies required. This paper therefore expands and builds on these five main activities in order to inform the higher-level competencies required for BRPs to execute rescues successfully; and to guide competence directives for a future qualifications framework.

This article provides, firstly, a brief summary of the relevant aspects of the new Act, as well as its prescriptions and requirements as boundary conditions. Secondly, it reports briefly on the relevant key aspects of competencies, with their specific applications as a cornerstone of the research for the main activities of BRPs. Thirdly, it presents the unique methodology of this research to build new theory. Fourthly, it reports the findings and, finally, proposes a conceptual competency framework. The proposed framework describes the higher-order competencies underlying the navigation assignment to be executed by BRPs. The resulting framework could be used to direct the industry and to trigger discussion about future competence measurement, based on its findings.

\section{Research question}

The CIPC, as Regulator of the rescue industry, currently pursues an ad hoc licensing approach and will do so until such time as a potential qualifications framework can be presented. A second, although future, requirement is the need for competence measurement of existing BRPs.

The research question is thus: 'What are the required competencies underlying the activities of the business rescue practitioner?'

\section{Background to rescue and rescue practitioners}

As this paper aims to build theory, this section provides a brief summary regarding the context of business rescue for the reader and explains how competency-related research gives direction with regard to constructing a competency framework for BRPs.

\section{Summarised essential background to rescue in South Africa}

In May 2011, Chapter 6 of the Act, as amended, came into effect. This allowed for a rescue procedure vaguely comparable to Chapter 11 in the United States (US) (Balovich 2002) and administration in the United Kingdom (UK) (Parliament of the United Kingdom 2006). Significant differences between the turnaround regimes of the US, Canada, UK and Australia, as well as that of South Africa (Pretorius \& Rosslyn-Smith 2014), suggest that to adopt directives from these countries can only supply principle guidelines but without details relevant to the competency requirements that are rescue-specific.

Currently, BRPs are licensed conditionally for a specific rescue project after being nominated by the relevant distressed company. Licences are allocated currently on the basis of relevant experience and appropriate references (track record), together with some elimination provisos to the granting of the once-off licence. No prescribed system or set of absolute competencies required for licensing practitioners exists. The CIPC, as the Regulator, has to date reported several problems that have arisen within the system. This study, therefore, aims to provide directives for qualifications, expertise, skills and competencies; firstly, to guide future licensing through gaining a better understanding of the exact competencies required for the practices that BRPs perform and, secondly, to address accreditation requirements and guidelines.

\section{Current licensing requirements from the Companies Act for rescue - sections 138 and 139}

Guidelines for BRP licensing rest on s. 138(1) of the Act, prescribing elements such as:

$[m]$ ember in good standing of a legal, accounting or business management profession; not be subject to an order of probation 
in; would not be disqualified from acting as a director of the company; and not have any other relationship with the company.

No mention is made of the specific knowledge, skill, ability or competency requirements except for those implied in the licensing requirements. These are left to the interpretation of the Regulator.

Further insight relevant to competency requirements is gained by understanding why BRPs may be disqualified; namely, in cases of incompetence or failure to perform the duties of a business rescue practitioner of the particular company. Section 139(2) of the Act describes incompetence as the 'failure to exercise the proper degree of care in the performance of the practitioner's functions; engaging in illegal acts or conduct; if the practitioner no longer satisfies the requirements'. Other hints are set out in s. 138(1) under the disqualifying elements of:

conflict of interest or lack of independence ... or if the practitioner is incapacitated and unable to perform the functions of that office, and is unlikely to regain that capacity within a reasonable time.

Here, competency is implied through the description of incompetency conditions, but without specific details about the competency element. Finally, as an officer of the court, the BRP has the responsibilities, duties and liabilities of a director of the company, as set out in ss. 75 (financial interests), 76 (conduct) and 77 (liabilities) of the Act. Again, no guidelines on the required competencies are given.

\section{Current task directives from the Companies Act for rescue - section 141}

Section 141 of the Act proposes the tasks of the BRP and gives legal directives to be followed. These tasks include taking control, investigating the affairs, preparing a rescue plan and implementing the plan, if accepted by the creditors through a vote. Additional research by Pretorius (2013) adds to the list of tasks in the Act a fifth task, namely, the supreme task of 'adhering to the statutory process'.

\section{Status quo of business rescue practitioner scenario - the first two years}

During the first two years of the Act's existence, 146 practitioners were licensed, 971 rescues were filed and several BRPs were removed for various reasons, excluding those who were forced to resign through numerous processes. Case law on business rescue is sparse but is on the increase (Lotheringen 2013, pers. comm.). Biannual meetings with BRPs and banks were held by the CIPC in order to improve communication and to address issues surrounding the tasks of the BRP. These were supported by several business rescue conferences by various stakeholder groups.

Typically, BRPs appointed to date have originated from the business $(63 \%)$, legal $(43 \%)$, accounting $(60 \%)$, banking and liquidation professions (Lotheringen 2014). The cumulative percentage is larger than $100 \%$ because some appointees have reported dual backgrounds. The BRP's main goal should be to navigate the financially-distressed business through turnaround procedures to normal operations or, alternatively, as stated in s. 128(1)(b)(iii), to construct a solution for creditors and shareholders that would result in a better return than normal liquidation. Alluding to competencies, Jacobs (2012) implies the inclusion of liquidators, referring to their competencies in accordance with Bradstreet (2010:207) as that of 'undertakers' and not that of 'doctors', as needed for rescue. What both authors allude to are the competencies associated with the different approaches, thereby giving some insight and directives to the competency principles pursued in this research.

This study responds to the need for research to conceptualise the competencies required during the process of business rescue and, simultaneously, to point out the key activities associated with the required competencies. This research proposes a conceptual organising framework for the BRP competencies, rather like the one that Shook, Priem and McGee (2003:381) proposed for entrepreneurs.

\section{Turnaround versus Rescue competencies}

At this early junction it is helpful to distinguish between the concepts of turnaround and rescue, as they may have a material influence on the interpretation of competencies. The distinction between turnaround and rescue contexts is important, as competency elements might focus on different aspects within a competency, despite potential overlap. The appellations of turnaround manager and rescue practitioner are often, mistakenly, used interchangeably, because of some overlaps in their processes, tasks, activities and functions - especially when the peculiar points of differentiation are not at all clear. However, their underlying approaches are inherently different, as described succinctly by Mindlin (2013), who contrasts the regime differences between the US Chapter 11 and South Africa's Chapter 6.

Turnaround is the American concept from the Chapter 11 regime (Mindlin 2013) for 'reversal in a firm's decline in performance'. Rescue, in contrast, also suggests the inclusion of firms that are in distress and ventures close to failure - as illustrated by the metaphor referring to the 'terminally ill' or 'intensive care cases'. Turnarounds are also handled mostly informally (voluntarily; and governed by more flexible legislation) and are generally done in the early stages of decline in order to return the business to 'normal' operations (Pretorius 2009). Chapter 6 states that firms must be financially distressed. The meaning of 'financially distressed', as defined in s. 128(1)(f) of the Act, includes the situation in which the company is unable to pay creditors or will become unable to pay creditors in the next six months. Rescue follows a much more legal and process-driven approach, with stigma-ridden consequences. Turnaround managers act under more flexible conditions, metaphorically reorganising the 'sick' business. The turnaround management could include the management that caused the business to decline in the first place. American research focuses mainly on turnaround strategies. The typical trigger point for initiating a turnaround hinges 
on two consecutive years of declining return on investment. A key differentiator from turnaround is that BRPs can pursue an alternative outcome, as the Act states that if the business cannot be rescued (reorganised) in its current form, the plan may consider a second option, namely, to seek a better (than liquidation value) return for creditors (s. 128[1][b][iii]), similar to an insolvency regime.

Developing a competency framework requires an understanding of both competency and competence. The next section explores the concepts and summarises the difference through a narrative example.

\section{Competency}

The path to a competency is by performing an act (Allio 2013:11) or a number of related activities. Furnam and Mansi (2011) describe competency as a 'state of being qualified, capable or proficient', through skills, knowledge and ability, for a specific assignment. Mirabile (1997:75) explains a competency (of an individual) as including knowledge, skill, ability or characteristics associated with high performance on a job, such as problem solving, analytical thinking or leadership, whilst some definitions even include individual motives, beliefs and values. Competencies apply not only to individuals but also to teams and companies where the search is for core competencies within an organisation (Klein, Gee \& Jones 1998:38). This article does not consider organisational competencies as its unit of analysis, but instead focuses on the competencies of the individual.

From many definitions in the literature reviewed by AbuelEaleh (2009), one can state that competencies include skills, activities, knowledge, mindsets, thought patterns, motives, attributes and traits that are the inputs required (what individuals do or have to do) to achieve success in their specific assignment. Competency is about what people can do, or their behaviour in executing a work assignment. Educators focus on competencies in an attempt to enhance or replicate them in other individuals. Recruiters use competencies for selection and job matching. Competency, in this article, refers to performance that can be demonstrated by an individual in executing the specific tasks and activities associated with the assignment of a business rescue practitioner. I choose the competency perspective, in line with Furnam and Mansi (2011:4) when they refer to management competencies. Especially of interest are higher-order competencies, similar to those which Boyatzis (1982) and Dulewicz (1999) refer to as supra-competencies. Competencies describe the 'what' of inputs and can be listed, categorised and prioritised based on expert knowledge of the assignment under scrutiny.

Competencies are associated with experience, previous learning and deliberate practice that may enhance the level of an individual's performance. Kahneman (2011:237) suggests that experts can access information stored in memory, which provides them with answers not accessible to the novice. So what comes intuitively is actually recognition of known and unknown patterns. They are also subject to heuristics and biases that may be beneficial for decision making under adverse conditions - typically those associated with rescue contexts.

In this article, building on Klein et al.'s (1998:40) metaphor approach, the researcher applies competency as a network of related and mutually-supportive skills, abilities, proficiencies and activities, similar to those described by Klein et al. (1998). Highly-competent individuals are said to have a 'disposition' for performance in the specific competency. There is often a high level of interrelatedness between associated competencies underlying a specific assignment; thus competencies can be judged either singly or in combination (Campion et al. 2011). It can thus be construed that competency implies superior or effective performance and, in this context, specifically that of the business rescue practitioner.

This study focuses on higher-order competencies, rather than fundamental competencies (Sonteya \& Seymour 2012:51), which include business knowledge, response abilities and technical skills. These fundamental skills are important; without them, the higher-order competencies cannot be contemplated. Competencies are understood mainly when skills, abilities and activities are demonstrated. Therefore, the key activities of the BRP were used as the basis for this competency framework, as the researcher believes that performance in a business rescue competency can only be understood by observing what BRPs do. Alternatively, retrospective analysis, as when doing a post-mortem or critical incident analysis, can give meaningful insights.

\section{Competence}

The relevance of competence is unassailable, as many studies identify incompetent managerial ability of owners and/ or directors of troubled ventures as being a key cause of business failure. Here, competence refers to performance and involves skills, knowledge and ability to execute successfully the tasks of leading the business to achieve its goals.

Although competence is not the focus of this article, its relevance to the phenomenon the research is investigating, namely, competency, is covered. Competency is generally associated with selection, whilst competence is associated with assessment and appraisal processes. Individuals are rated on competence frameworks on a scale ranging from incompetent to competent (Mirabile 1997:74), or on various level scales ranging from novice to competent, to proficient, to expert or even master performers of the relevant tasks (Dreyfus \& Dreyfus 1980). Various performance levels exist to describe 'not competent' on the one end and 'highly competent' on the other.

Competences include standards, levels of achievement, results or desired states of performance (what individuals have to achieve) for high levels of success in their specific assignment. Competence is about how well people perform or execute an assignment. Evaluators of competence focus 
on competences in order to coach, mentor and enhance the performance of a specific individual. Competence, in this article, refers to performance levels that can be demonstrated by an individual in the execution of the specific tasks and activities associated with the assignment of a business rescue practitioner. Competence describes 'how well' the competency is performed; thus the outputs are measured and rated on a scale of performance, again judged by an expert with knowledge of the assignment under scrutiny.

Individual competences are often explained to the lay reader by using the analogy of chess (Dreyfus \& Dreyfus 1980). Typically, the novice chess player knows all the rules, moves and abilities of pieces on the board. The actions of novices are mechanistic and they follow 'recipes' at best. The chess master, however, can read patterns, strengths and positions in the board layout, applying complicated move sequences to the contextual situations. The master intuitively knows about alternatives, often based on previous similar and nonsimilar experiences. The level at which the same actions are performed thus varies with the proficiency of the individual.

To explain competency and competence is important (Teodorescu 2006:27). Without labouring the point, it is suggested that the following narrative picture be used in order to understand the difference relevant to and typical of BRPs. Say, for instance, a young insolvency lawyer wants to become a BRP. He has particular competencies such as a legal qualification, insight into the Act, can undertake court procedures and filings, wants to represent the interests of clients, is approachable and has negotiated before - he is a proficient lawyer. To navigate the rescue he must perform the tasks of feasibility analysis and viability analysis in order to analyse the turnaround situation and to determine a 'best' future position. At face value, his existing competencies do not match the competencies required; so on a list of required competencies he cannot show historical proof of many competencies. In contrast, his father, who is a chartered accountant and experienced Chief Financial Officer of four companies, appears to have several of the competencies required for the rescue navigation assignment. Both, however, have low competence. The son is a 'novice', as his proficiency in executing the tasks depends on applying the guidelines of the Act and the literature procedures identified, as well as following outside advice. The father, by contrast, may be 'capable' if measured on BRP fundamental competencies. However, any firm that needs to file for rescue would like to appoint an expert to drive their rescue, rendering the son (definitely) and father (probably) unsuitable for appointment.

My interest in this article is more in competency than competence. The next section describes the research process used to elicit directives for the competencies required and eventually to propose the competence model.

\section{Research method and design}

The research aims to propose a competency framework developed, firstly, from the prescribed tasks that BRPs must perform when executing a business rescue in South Africa under Chapter 6 of the Act and, secondly, on the main activities that they must perform in order to achieve the tasks. It therefore involves description; understanding but mainly sense-making and interpretation supplied by the subjects.

\section{Research design}

Table 1 summarises the research design and is followed by a detailed description of the design elements.

In attempting to answer the research question, the researcher was aware of his own beliefs, philosophical assumptions and methodological values. These assumptions could influence how the research was conducted and are stated in order to understand the 'intellectual climate' in which the research was conducted. The theory of knowledge (epistemology) of the researcher describes how one can discover underlying principles about social phenomena and how one can demonstrate knowledge. The researcher's personal experience with a business failure ignited his interest in business rescue. At the same time, as an academic and experienced turnaround consultant, he has a preference for factual directives. To mitigate his biases and subjectivity, a structured data-gathering method (modified 'interview to the double') was used to capture the activities and experiences of the subjects during their evaluations.

An ontological position comprises the researcher's view on the very nature and essence of the research reality. The researcher is an objective realist who believes that knowledge comes from facts associated with real-life cases

TABLE 1: Research design of this study.

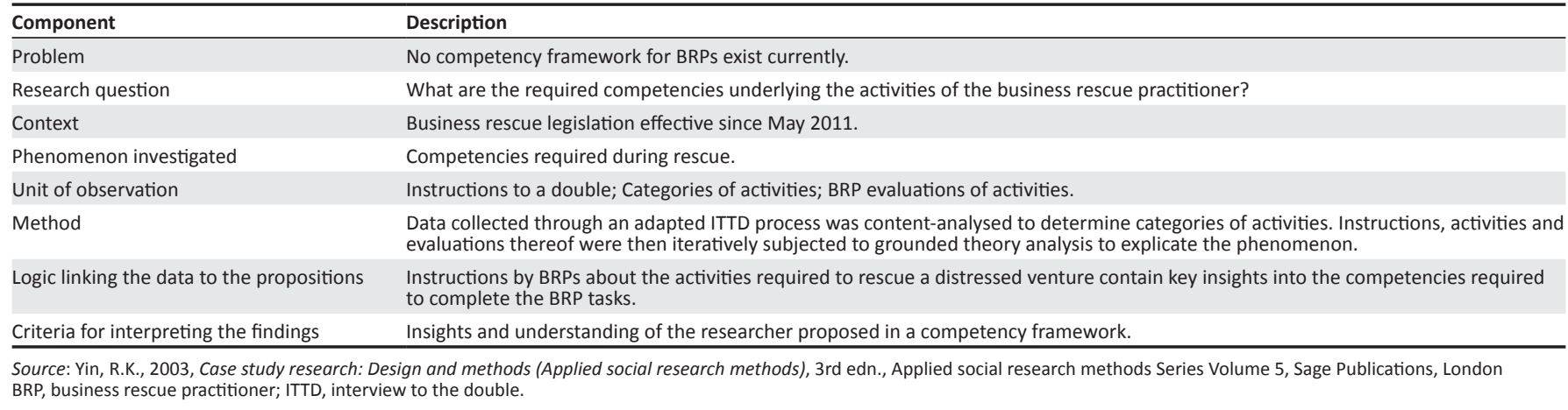


and their context. If the researcher found repeated mentions of practices and praxis, he could generalise from them. His interest was, mainly, to identify directives to guide the future education of BRPs.

\section{The roots of the 'Interview to the Double'}

The research applied a technique called 'interview to the double' (ITTD) in order to identify the practices and praxis in question. Nicolini (2009) postulates that the ITTD process requires interviewees to imagine that they have a double who will take their place in their workplace on the following day. The interviewee-instructor is then asked to provide the necessary detailed instructions that will ensure that the interviewer-double is not unmasked.

The ITTD is generally used in one-on-one interviews and is reported in the literature as an application to raise the awareness of subjects that they, as a 'homogeneous group', are bearers of valid and precious know-how. Typically, the interviews are carried out during training workshops with the researcher acting as the double and the subject as the instructor. The subjects are not interrupted and their long monologues, often lasting hours, are tape-recorded and transcribed.

The original intention of the technique was to expand the ITTD as a method of data collection and as a way of understanding and representing practice (Bruni \& Gherardi 2001; Gherardi 1995; Nicolini 2006; 2007). It is from this perspective that the adapted process is described. This primary data collection was done so as to access BRPs directly, in one session rather than in consecutive individual interviews. To execute this successfully, the ITTD process was administered to all BRPs in one session, using slides to post the specific instructions whilst each BRP responded by writing the instructions personally.

The ITTD was chosen for its ability to eliminate self-serving bias, compared with surveys, where subjects must rate their performance. It also contains a form of anonymity and neutrality; the focus is on outputs, whilst it forces the subjects to reflect on what they do in practice to compile the instructions. ITTD has been used to study workers, nurses, managers and entrepreneurs.

For the BRPs, it was an opportunity to reflect on and progressively enrich the image of their own work. The process of data collection thus constituted an opportunity for the BRPs to expand their possibility of acting in the world. The adapted tool was revealed to be useful, both with regard to capturing the experience and to enriching it through reflection.

\section{Sample}

A purposive sampling strategy was used. BRPs who had been licensed at least once before were selected for participation. The final sample consisted of 47 BRPs from a population of 105 (at the time) who had been licensed at least once previously. Whilst biographical data for each BRP was available from CIPC, it was not accessed for this research. The sample contained 26 (55.32\%) senior BRPs, 16 (34.04\%) experienced BRPs and five (10.63\%) junior BRPs.

\section{Data collection procedures}

Firstly, Chapter 6 of the Act relating to task prescriptions was studied in order to guide category development for the BRP task groupings of practices. Secondly, a modified ITTD process was applied to BRPs, during a workshop setting, to collect primary data. The ultimate output of the full study was to set an education and qualifications framework based on BRP competencies.

The phenomena investigated were initially the practices and praxis associated with the tasks of practitioners during the business rescue process. Using the ITTD process required the subjects to include, firstly, their perspectives, thinking and decision-making priorities and, secondly, their experiences of real-life cases that they had executed within their specific contexts. The boundaries between the subjects and the practice contexts were not clear, as they had had prior involvement with their own experiences (rescues performed). This meant that the researcher could pursue all angles of evidence to seek convergence and divergence. In addition, because their experiences were recent, there was sufficient access to short-term memory and associated learning from their practical experience.

Subjects were invited by the regulating authority (CIPC) to attend a bi-annual workshop. After other workshop formalities, presentations and discussions, a structured process was introduced by the researcher in which BRPs were asked to give seven to 10 written instructions to a 'double' who would replace them in a rescue for which they had just been appointed.

Subjects participated voluntarily. It was found that they were relaxed during involvement, as shown by their asking clarification questions and even bantering about potential instructions. It is believed that these positive conditions led to unbiased sharing and meaningful contributions drawn from the prompting of their perceptions and experience.

\section{Modified data collection process for the 'interview to the double' in this research}

After the research had been introduced to participants, an instruction was displayed on two slides, one describing the situation and another with the specific instruction to the BRPs. Their exact content was as follows:

- Situation (slide 1): You have been appointed as BRP to a company. Unfortunately, before you could investigate and with no pre-assessment, you have to go away urgently and you send a 'double' to act in your place. There will be no contact between you and the 'double' after you have given him instructions.

- Instruction (slide 2): Identify a minimum of 7-10 absolutely key tasks to be deliberately performed by 
this person leading up to the business rescue plan's substantial implementation. Focus on what he or she must do to ensure smooth and successful business rescue execution and process.

An example of a sticky note with the required format (see also Figure 1a - left picture) was shown at this point and an opportunity given for clarification questions that were repeated and answered so that all participants could obtain maximum clarity. Thereafter, BRPs were given the opportunity to complete the instructions they identified as key instructions on separate sticky notes. Sufficient time was allowed for all to complete this task.

After writing the instructions on the 'open' sticky note, through structured facilitation and guidance, subjects were asked to rate the tasks for importance, transferability of the task, knowledge level required, skill classification and ranking. Each evaluation task was completed before moving to the next, as the evaluation scales differed.

On completion, subjects were asked to attach each sticky note individually to one of four large boards, marked: (1) take control; (2) investigate the affairs; (3) preparation of the plan; and (4) implementation as prescribed by ss. 140 and 141 of Chapter 6 of the Act. Figure 1b (right picture) shows the

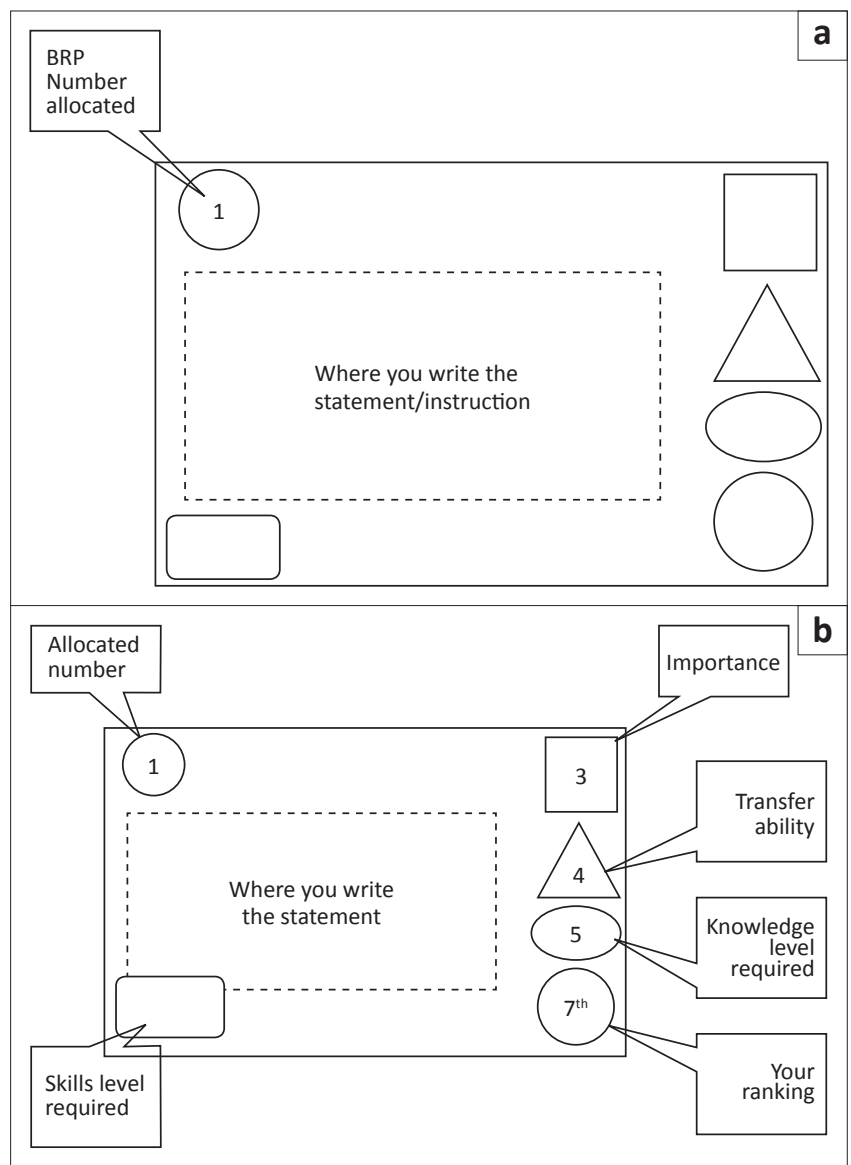

BRP, business rescue practitioner.

FIGURE 1: Format of the sticky notes at the beginning and after the facilitated process. format of the final sticky notes after the phased development process and addition of the individual components.

\section{Strategies for ensuring quality data and interpretation}

There was only one source of evidence (BRPs). The researcher checked quality as the collection process progressed by asking questions for underlying understanding of the instructions. As the focus of this phase was mainly exploratory (asking 'what'), the ITTD process also elicited 'how' things were perceived as the subjects described them, thus using 'explanation building' in order to improve internal validity (Yin 2003:34). The BRPs wrote their own responses.

As there was only one researcher, he depended on several readings of the instructions (responses) given. On the basis of the researcher's experience in rescue and extensive preparation, meaningful categories could be constructed. Once categories were obtained, each instruction was divided into subcategories in order to confirm the specific function within the category to which it was allocated. This led to the original category being challenged and, occasionally, recategorisations took place during iterations, until saturation point was reached.

Finally, when an instruction contained more than one category concept, the researcher judged it for the primary category, based on the spirit of the instruction.

\section{Data analysis}

The subjects' cognitive experiences and knowledge of business rescue were the main source of data. After word-for-word transfer of the instructions to an Excel ${ }^{\circledR}$ spreadsheet the key practices and praxis (first order) were identified, coded, categorised, recoded and re-categorised, through content analysis, so as to extract the facts, essence and spirit of the instructions. Activity categorisation (second order) was then done by the researcher. The iteration process was repeated at least five times until a point was reached where additional iterations would have no material bearing on the category outcomes. Practices and praxis led to activities in support of the tasks on a business rescue (Pretorius 2013). From insights gained through both inductive and deductive reasoning and applying grounded theory principles, relevant competencies were explicated and a framework proposed that indicated the competencies and their potential relationships to the BRP tasks at hand.

Although there was only one key source of evidence (the subjects' instructions), the researcher used grounded theory principles (Corbin \& Strauss 1990; Henning 2011:138) in order to extract as much richness as possible. The 47 subjects supplied 440 individual instructions that were interpreted by the researcher. Each instruction contained the ratings and ranking, although some missing values were observed.

Each instruction was coded for collective categories that surfaced as they were read, interpreted and reread several times. Categories appeared and were refined, until 15 final 
TABLE 2: Activity categories with typical associated practices and praxis.

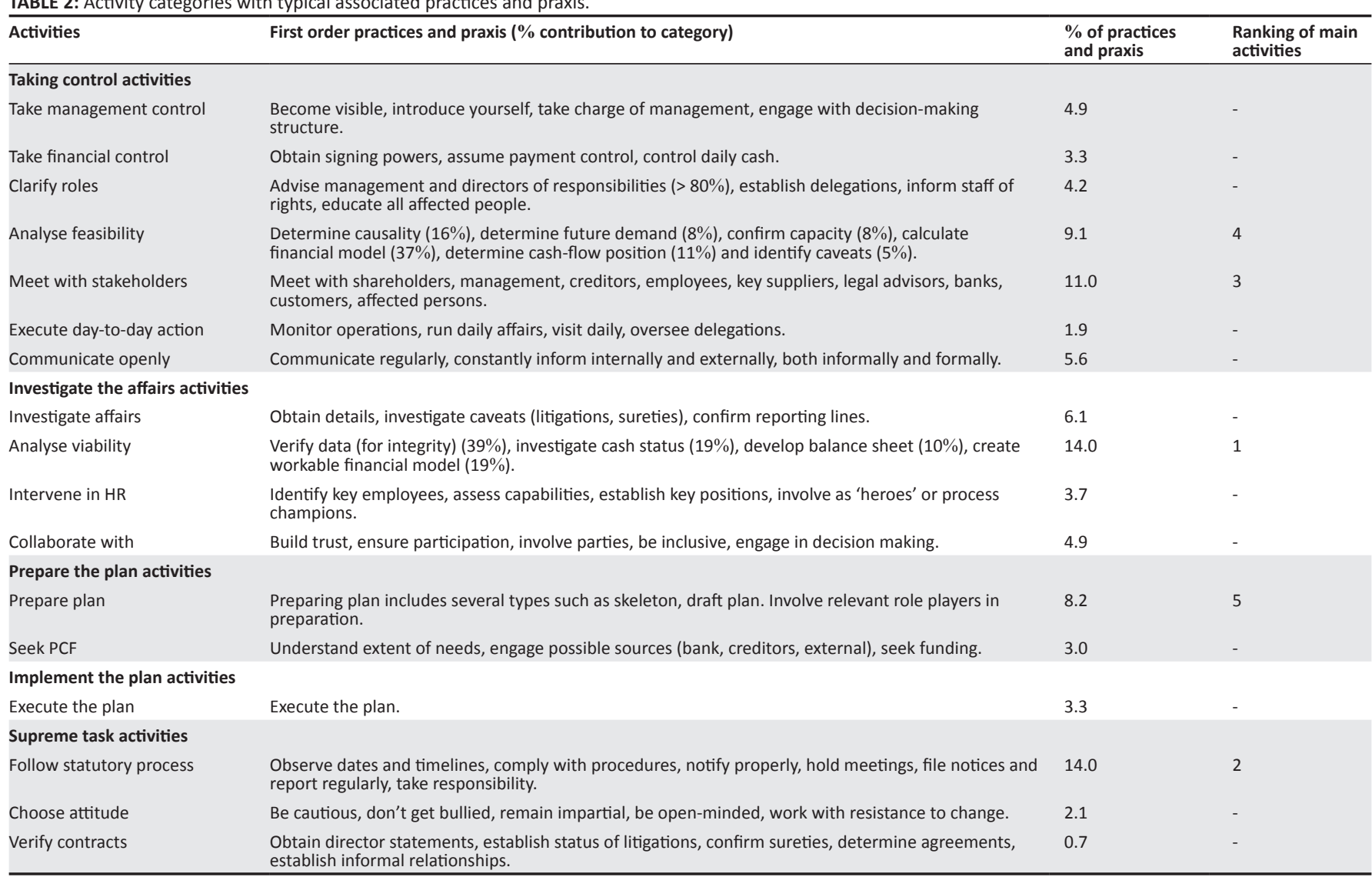

Source: Pretorius, M., 2013, 'Tasks and activities of the business rescue practitioner: A strategy as practice approach', South African Business Review 17(3), 1-26 PCF, post-commencement finance.

categories of activities were determined (see Table 2). Each category was measured based on the number of times it was mentioned and a percentage could thus be calculated. Five main categories were identified and formed the focus of further analysis. Interrelationships between activities, phases and tasks were also identified and reported in the discussion of the findings.

The research style was exploratory, designed to identify and describe the activities (directed by first-order practices and praxis) and how they are applied in the execution process of the business rescue tasks. Eventually, after understanding how activities related to the business rescue process, the subjects evaluated the main activities. On the basis of the overall insights gained, the researcher conceptualised and proposed a competency framework for discussion.

\section{Results}

\section{Activities of business research practitioners to execute the tasks and inform competencies}

Extracting from the practices and praxis (first order), Table 2 shows that the five main categories (second order) of activities, in order of size (but not sequence) were found to be: viability analysis, complying with statutory requirements, meeting with stakeholders, analysing feasibility and communicating openly. More detailed practices and praxis within the activities and their percentage mentions within the categories are also visible. These are important, as they inform the competencies to some extent.

Several of the activities not identified as 'main' appeared to be associated with the main five activities as well as being interrelated (not determined statistically). Each main activity is now explored briefly in search of competency guidelines and these relationships further described. Main activities are reported in sequence rather than number of mentions.

Feasibility analysis (9.1\% mentions) in business rescue is the first step and suggests that all the elements required for a potentially viable business model should exist; if these are combined appropriately, a profitable venture could ensue. Typically these elements should include future demand, capacity (resources, process and assets) to generate an economically-profitable model, cash generation and no caveats (fatal flaws or constraints). Practitioners must judge whether or not they have a business to save. This is required for the first creditors' meeting. Gottfredson, Schaubert and Hirzel (2008:29) equate this feasibility analysis to 'determining the point of arrival' and the viability analysis as 'determining the point of departure' in the turnaround process.

Frequently, the judgement of feasibility is made on the basis of perceptions, insights, experience and intuition of the practitioner, founded on the initial information as gathered before the first creditors' meeting. The BRP reports this to 
creditors if he believes that there is a reasonable prospect of creating a rescue plan in order to do so. Often, a feasibility judgement suffers from a data integrity liability (Pretorius \& Holtzhauzen 2008), which is addressed by the viability analysis where verification is done. Once identified, the BRP embarks on a proper viability analysis (due diligence) so as to overcome this liability.

'Meet with' stakeholders (11\% mentions) does not inform the reader directly. Meeting the different role players is a praxis (activity) that enables the BRP to take control, clarify roles, improve collaboration, open communication and, to a lesser extent, verify contracts, intervene with staff and execute day-to-day operations. Meetings are crucial to the statutory process, with prescriptive meetings being mentioned in the Act.

Viability analysis (14\% mentions) in business rescue refers to a detailed review of all aspects of the rescue event and context, which includes causality, business model (profit), financial model (cash), legal drivers (contract, securities) and any relevant material that may influence the viability of the rescue plan presented at the second creditors' meeting for implementation. Viability follows from the feasibility analysis. Midanek (2002:23) refers to it as a 'glass assessment', which is in line with Kierulff and Petersen (2009:45), who postulate that understanding of the financials, cash flow and verification of data (data integrity) are key turnaround management practices. Viability analysis happens in Phase 2, when investigating the affairs, following the initial feasibility analysis that happens in Phase 1, whilst taking control of the business and preparing for the first creditors' meeting.

Preparing the rescue plan $(8.2 \%$ mentions) is a key instruction witnessed by the practitioners but with no detailed practices and praxis. Some schools of thought are starting to suggest that this is the unique task of the BRP. Obtaining post-commencement financing is the only other practice in this category. Several of the other practices and praxis, for activities such as feasibility and viability analysis elements, are directly-associated prerequisites for achieving this activity.

The 'supreme task' to follow statutory process (14\% mentions) is not described directly in any ss. of the Act but, being part of the legal framework, it suggests that it is the ultimate guideline with which the BRP needs to comply. Without compliance (there is no partial compliance, as shown by the ATE judgment [2012]), none of the other tasks is possible. BRPs were very cognisant of this in their instructions, with multiple mentions made of this fact (the second-highest number of mentions).

Whilst not constituting a single task, taking management control, taking financial control and clarifying roles together contribute $8 \%$ to the mentions. Scherrer (2003:53) also suggests the inclusion of financial, production, marketing and distribution control in this category for 'taking control'. It is relevant at this junction to highlight the fact that an unknown number of rescues have entered implementation of rescue plans involving turnaround. It is, however, suspected to be relatively low and may be the reason for so few practices and praxis being reported in the category associated with implementing the plan. Table 3 describes the five main activities for competency-related elements by describing the evaluations of each to improve our understanding of the underlying structures.

\section{Discussion of findings, key theoretical components and insights from the study}

To enhance meaningful coverage of the findings, this section deliberates each aspect of the findings as they appeared during the process. The findings, the first in this field, are then elaborated on and explored in order to gain an improved understanding so as to guide the proposal of a framework of competencies in BRPs.

A range of specific practices and praxis was determined through the ITTD process as first-order elements (see Table 2). These collapsed into 15 second-order activities, with varying percentage contributions. Clear activity categorising could be done aligned with the tasks of the BRP. The five activities encompassing analysis of feasibility and viability, meeting with stakeholders, preparing the rescue plan and then implementing it, constituted 55\% of the total activities mentioned. Whilst activities were categorised under the different tasks, there were large overlaps in the phases and timing of activities over the different tasks.

BRPs could identify the key activities (see Table 3). They did so by including them in the instructions to the double. The first-order practices and praxis are fairly detailed about 'what to do' - in line with what competencies are about. From these, the main activities could be identified after being derived through the iterative process of this research.

Rescue practitioners' ratings of the five main activities, based on importance, suggested that all five of the key activities were highly important, with ratings between $84 \%$ and $91 \%$. This is to be expected, as only the five most-mentioned activities were used for this part of the analysis, thus validating their inclusion. The nature of the modified ITTD procedure also required BRPs to focus on important aspects as a natural part of the process, thus extracting the key elements.

Transferability was investigated, as it points to 'how easily' the practices and praxis can be delegated for execution by the double (or someone else). Transferability is important and is associated with delegation on the part of executives running large numbers of people and functions. In general, lawyers and accountants execute consulting roles that require independent specialist advice and are somewhat removed from the general management skills required. The problems of distressed firms are rarely limited to only legal or financial problems (TMA 2009:4-8); therefore business-related aspects 
TABLE 3: Subjects' evaluations of the five main activities associated with business rescue tasks and judgements about competency requirements.

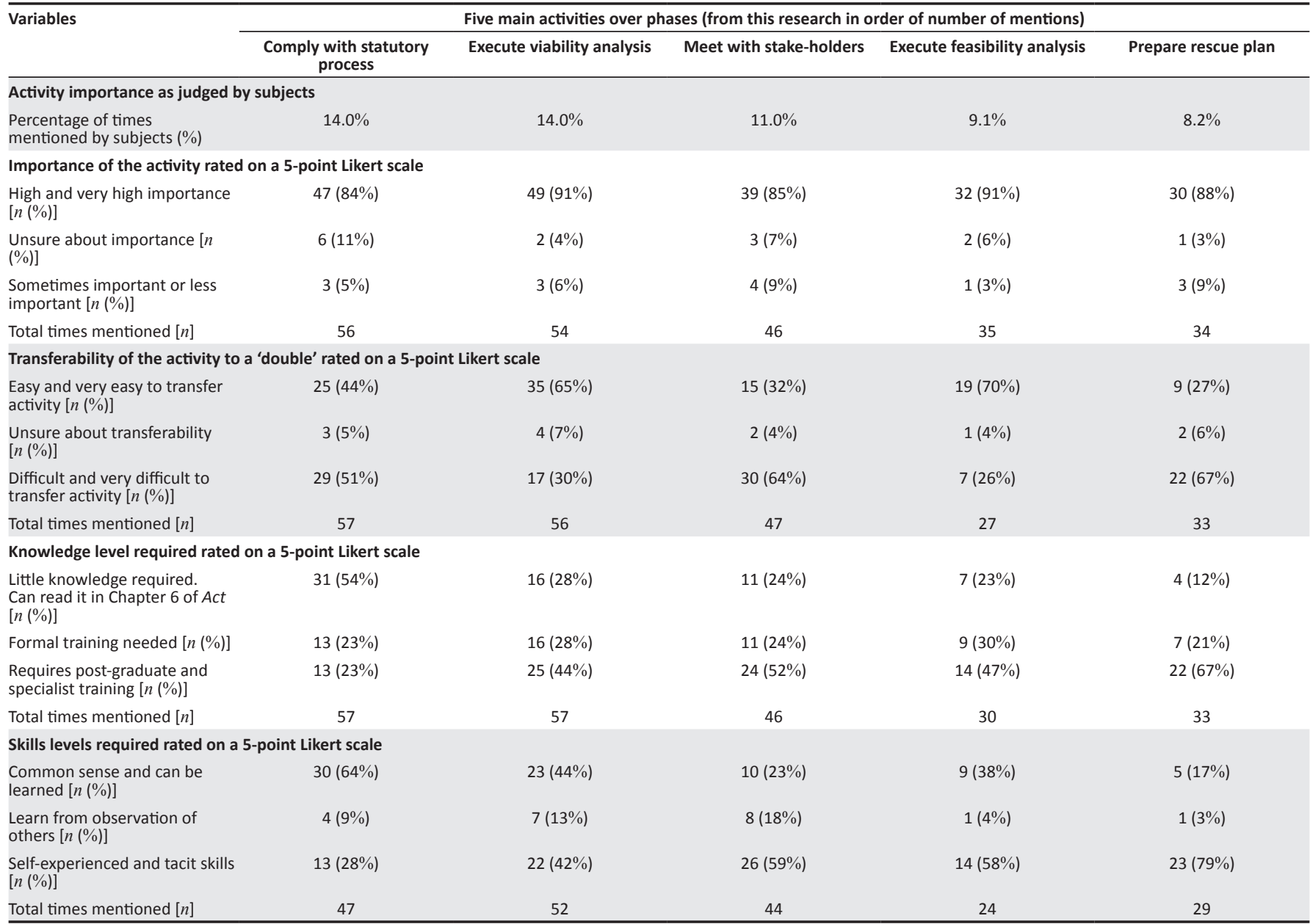

Notes: All figures rounded-off for ease of reading.

seem to take preference. Table 3 shows that BRPs suggested that practices and praxis associated with the execution of the feasibility analysis were the easiest to delegate (70\% easy or very easy) and preparation of the plan the most difficult to delegate $(67 \%$ difficult or very difficult). Meeting with the stakeholders was rated the second most difficult to delegate (64\% difficult or very difficult). Inability to transfer a task suggests higher demands on the competencies required to function in the BRP role.

Of interest was that only $51 \%$ of the BRPs felt that complying with the statutory process was difficult or very difficult to delegate. This might direct focus toward basic compliance issues such as 'inform stakeholders' and 'call creditors' meeting', which are easy to delegate, compared with 'report any wrongdoing', which must be initiated by the BRP through prescribed court processes.

The task of preparing the rescue plan can be considered as being the central task of the rescue practitioner, distinguishing the BRP from the general tasks associated with general business management proceedings and which lead to its being rated as the most difficult to delegate. (This observation should, however, be interpreted with care, bearing in mind the potential bias of BRPs to protect what they consider makes them unique for the job.) Sufficient support was therefore found for the BRP's knowledge, the key activities of which are transferable.

Rescue plans do not differ significantly from business plans prepared for start-ups (submitted to financial or venture capital institutions), barring a few technical additions such as the liquidation value requirement. Minimum statutory requirements for the rescue plan (s. 150 of the Act) appear insufficient for affected persons to make meaningful and informed decisions. What may be of more relevance to consider is the ability to access and source postcommencement finance.

Knowledge (which underlies many competencies) is important, as it suggests familiarity with and awareness of the relevant facts, processes and insights required to make sense of the issue at hand when rescuing a distressed business. Metaphorically, the difference in requirement at advanced levels may be compared to the difference between that of a general medical practitioner and a specialist.

BRPs could discriminate between the activities based on knowledge requirements, but no clear patterns emerged, except for that of compliance with the statutory process. 
Compliance with statutory processes was rated as having a low requirement for specialised knowledge. Fifty-four percent of the subjects suggested that compliance issues could be read from the Act and required no specialised knowledge on the part of the BRP. Van der Linde (2008), conversely, suggests that there are many interpretations and complexities such as liabilities, pre-existing contract effects and encumbered assets that may increase complexity. In practice, case law is developing, whilst BRPs appear to employ legal specialists as part of their backroom teams in order to deal with such contingencies.

Preparing the plan was also judged to require postgraduate and/or specialist knowledge, as mentioned in $67 \%$ of the cases, compared with the activity of 'meeting with', which was rated by only $52 \%$ as requiring specialist knowledge. These knowledge-requirement ratings should also be interpreted in the light of a possible self-serving bias that may be associated with rating oneself. As most BRPs in the sample do not necessarily have relevant postgraduate business qualifications, they might have rated the formal knowledge requirement as being less important than others. In fact, anecdotal evidence could probably support this in practice. A further explanation might be that some of these activities could be achieved through the involvement of specialist team members, such as lawyers for the statutory process and accounting professionals (to some extent) for the viability analysis and its detailed subprocesses, such as forensic audits.

Compliance with the statutory process was reported to require mainly common sense $(64 \%)$, whilst preparing the plan $(79 \%)$, meeting with stakeholders (59\%) and feasibility analysis (58\%) were considered to require higher-level skills, with tacit knowledge based on self-experience and possibly intuition.

In this instance, the self-serving bias might have operated in reverse to the knowledge requirement, so that BRPs rated tacit knowledge as being more important. An interesting observation is the apparent discrepancy between the relevance of tacit knowledge for feasibility analysis (79\%) and its previous rating of being easily transferable (70\%). The feasibility analysis is crucial for the BRP at the early stages before the first creditor meeting, in order to inform creditors of the BRP's belief that there is a 'reasonable prospect' of saving the business (s. 147 of the Act). In this study, to a lesser extent, executions of the viability analysis suffered a similar discrepancy $(42 \%$ tacit knowledge requirement with $65 \%$ transferability).

\section{Answering the research question: 'What are the competencies required by business rescue practitioners?'}

The rescue process has phases, tasks and 'infliction points' (key requirements of the statutory process). These overlap and intersect to some extent, but most activities require execution and immediate attention early on in the rescue process. This high intensity of activities reduces over time, whilst not losing any of the focus (Pretorius 2013).

Building on and looking beyond the tasks, practices and praxis toward the underlying competencies needed to execute the rescue navigation assignment, along with its activities, is complex. The BRP needs to apply perceptive skills in their analysis, evaluation and interpretation of the event and specific context; judge and choose the appropriate alternative through decision making; and develop a rescue plan that will be supported through integration. This they do whilst at the same time managing (supervising) the distressed business's continued operations. They also apply collaboration and negotiation skills in order to engage other relevant parties (persons) to participate and invest in the venture. When and if the plan is supported, they lead the implementation of the operations. To navigate a business rescue successfully, the BRP requires both higher-order and fundamental competencies. These competency requirements should direct education of BRPs within the contextual technical knowledge associated with the rescue tasks to be performed. Figure 2 demonstrates these competencies, showing the interrelations between them as well as how they relate to the tasks of the BRP. Each higher-order competency is explained briefly.

\section{Sense-making}

Sense-making is described as the motivated, continuous effort to understand connections (between people, things, process and events) in order to anticipate their trajectories and so act effectively (Klein, Moon \& Hoffman 2006:71). Therefore, sense-making is central to the identified key activities of feasibility and viability analysis in order to address investigating the affairs of the business. This may require higher-level perceptual capacity in order to understand factual and intuitive data and knowledge, seeing the unseen patterns leading to rapid judgements referred to as System 1 thinking by Kahneman (2011:59). For rescue, it means insight into causes of distress (Pretorius 2008), product demand, capacities, economic models, cash-flow effects, fatal flaws

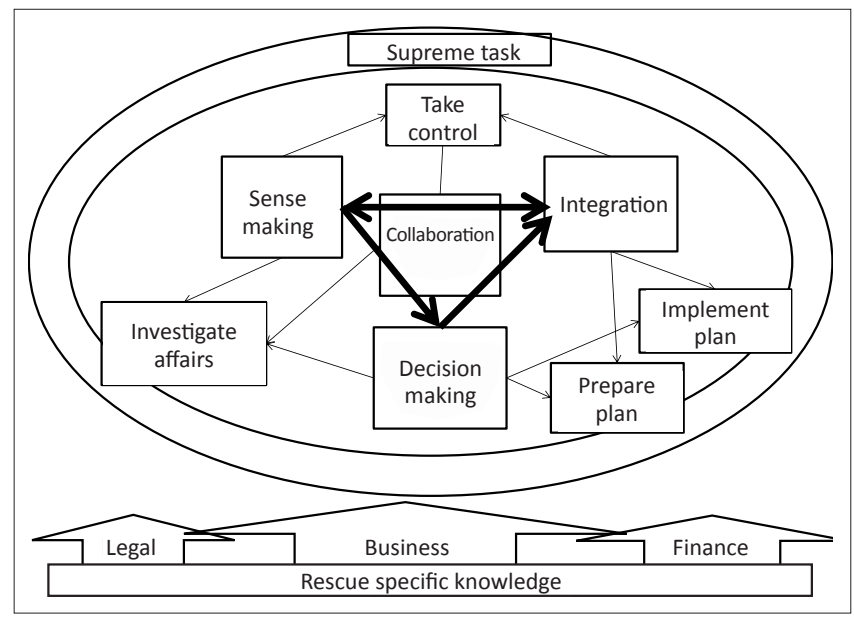

Source: Author's own compilation

FIGURE 2: The relationships and interrelationships between the higher-orde competencies required by a business rescue practitioner, rescue tasks and knowledge requirements. 
and constraints, financial ratios and comparisons and more. Specific techniques are reported by BRPs so as to execute this function. Sense-making mainly, but not exclusively, underlies the feasibility and viability analysis activities. Boyd (2011:37) proposes that the turnaround leader analyse market perceptions in an attempt to explain the plight of the business. During the first weeks of a rescue, the BRP suffers severe data overload; part of his strategies toward-sense making may involve the use of decision-making heuristics such as verifier determinants (Pretorius \& Holtzhauzen 2013) and intuitive biases (Kahneman 2011).

Underlying sense-making is the perceptual capacity to do the following: quickly identify crucial information; recognise patterns; analyse; encode new information; have an understanding of own cognition and performance; understand current knowledge; engage in offline processing; identify problems; and develop an enhanced ability to make rapid and accurate judgements without detailed analysis (heuristics).

From Figure 2, it is clear that rescue-specific knowledge comprises business knowledge, mainly supported by financial and legal knowledge.

\section{Collaboration}

Collaboration is the competency underlying the key activity of 'meeting with' and communicating openly and regularly with all affected parties. As mentioned previously, meeting with all affected parties is the praxis to achieve all the tasks in rescue. The complexity and vast array of practices and praxis of business rescue suggest that execution cannot be achieved without the participation of all the parties such as creditors, employees, shareholders and/or management and financiers. To perform well on collaboration, the BRP must establish trust, involve affected parties, negotiate deals, communicate effectively, transfer (delegate) functions as part of managing the business and apply inclusive techniques to ensure optimal information sharing. Boyd (2011:37) suggests that collaboration, as the first crucial step in turnaround, is to 'solidify personal leverage', hinting at obtaining board support and establishing trust through prudent promises. This is enhanced by open communication, involvement and negotiation abilities.

Underlying collaboration is the ability to build trust, involve others, participate, negotiate, delegate, manage and bring inclusivity, even within an often hostile process. Nikolaou et al. (2007:297) point to these as being part of facilitation competency in a change agent. Collaboration also requires skills associated with managing cross-functional teams (Leinwand \& Mainardi 2013:2), which is typical in rescues.

Collaboration is the central competency through which sense-making interacts with decision making and integration and vice versa. In business rescue, the Act is only prescriptive about the involvement of creditors and employees as affected parties in the rescue process. Once the BRP presents the plan, it is the creditors who vote on the plan going forward. A co-created plan which involves high-level collaboration, therefore, stands a better chance of being accepted at the second creditors' meeting.

\section{Decision making}

Decision making is central to all the interventions in the business rescue process and the key activities for preparation of the plan; Baba and HakemZadeh (2012:832) state that decision making is at the heart of management practice. The process requires the BRP to make judgements on 'reasonable prospects' (s. 147 of the Act), the best position and the business's future at different infliction points. Basic problem-solving techniques are inherent to this process. Fundamentally, after making sense, the BRP must strategise (in collaboration with affected parties) to rescue the business. This requires weighty, serious and far-reaching decisions. The specific elements, tools and processes for decision making are described widely in literature, so need not be elaborated on here.

Underlying decision making is the ability to: apply problemsolving processes; evaluate options; exercise judgement; and make rapid and accurate decisions, with or without detailed analysis and strategising.

\section{Integration}

Integration refers to the ability of the BRP to incorporate relevant pieces (often loose standing) of the 'puzzle' in order to function sensibly together as a whole (connecting the dots). Alfalla-Luque, Medina-Lopez and Dey (2013:800) suggest that integration considers information-related elements of resources for coordination, management and sharing between units of production and forms the basis of, for example, integrated logistics systems. Essentially it is aimed at, firstly, synthesising all loose ends into the rescue plan and, secondly, the implementation of the plan.

Integration links closely to the synthesising of existing elements into new formats. The relevant resource factors may be part of the internal business functions and operations but may also come from outside the business itself (creditors, debtors, funders, the BRP's network). Integration is a prerequisite for the writing of the plan and the eventual implementation thereof, whilst the BRP later withdraws his or her involvement in the management as the substantial implementation point is reached. Integration depends heavily on sense-making, because this is where links between apparently disconnected resource factors and functions are made. Integration links closely to decision making as well and is also highly dependent on decisions taken for execution of the plan.

Underlying integration is the enhanced capacity to engage in: offline (System 1) processing, connecting the dots, synthesising, creating new solutions, proposing alternatives and anticipating effects. 


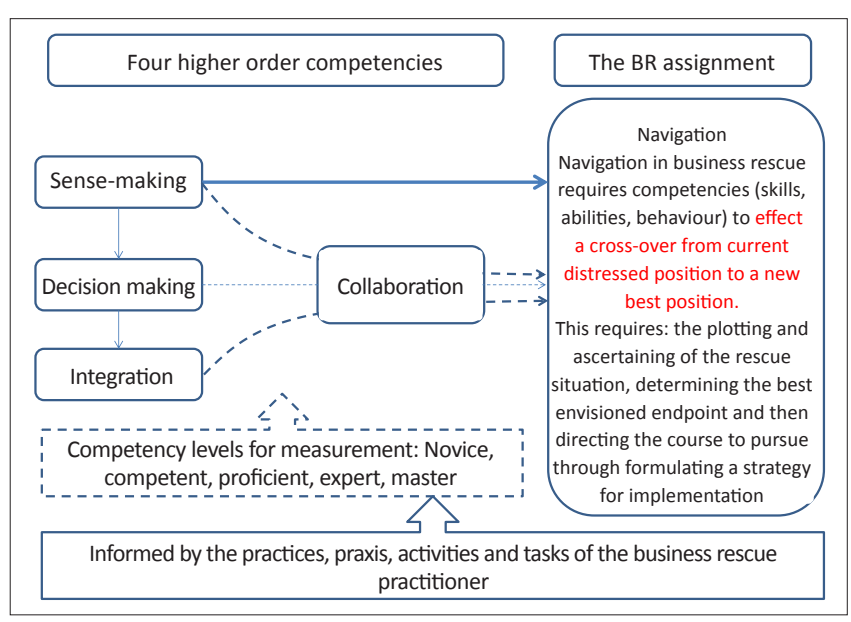

Source: Author's own compilation

$B R$, business rescue.

FIGURE 3: The relationships between the higher-order competencies required by a business rescue practitioner to navigate a business rescue.

\section{Navigation as the main assignment}

Navigation toward the new 'best' position is what brings the competencies together. To navigate successfully as a BRP, the four higher-order competencies should be supported by rescue-specific knowledge; something that is easier said than done. Moreover, they cannot be addressed in isolation but should be used in 'concert', as described by Schoemaker, Krupp and Howland (2013:2). The interdependence of the competencies, however, suggests that any business rescue education should include development of these competencies, together with specific technical knowledge. The specific knowledge will probably be supported by the application of known techniques such as ratio analysis, verifier determinants, delegations, checklists and many more so as to enhance the use of the competencies. Further research into the techniques that BRPs use to ensure sensemaking, collaboration, decision making and integration would be relevant.

\section{Competency summary}

The four higher-order competencies are therefore interrelated and can be considered to be 'unspecific'; they could be applicable to Chief Executive Officers and leaders in general. Trahms, Ndofor and Sirmon (2013) highlight the role of the turnaround manager as strategic leader. Each competency depends on a network of skills, knowledge and activities within the specifics of the individual rescue context. All four competencies contribute to the assignment of the BRP - what was suggested as 'navigation'. Navigating a business rescue suggests a cross-over from the current distressed position to a new best position (see also Figure 3). It should be noted that 'best' position is specified, as the BRP is required to identify the best alternative, which should not be confused with the alternative of finding a better return for shareholders.

\section{Conclusion}

This study expanded on the tasks and activities of BRPs during business rescue as identified by Pretorius (2013). Five tasks and 15 activities were derived from the practices and praxis supplied by the BRPs when instructing a double to execute the rescue. Five main activities were explored further in order to understand more fully their relationships to tasks: importance, transferability, knowledge requirements, skills requirements and rankings. BRPs could discriminate between these activities based on the above, thereby directly informing the higher-order competencies.

Finally, the activities gave direction to the higher-order competencies required by BRPs and proposed as the competency framework. These higher-order competencies culminate in one assignment of the BRP, namely, that of navigation. Navigating the rescue is the task assigned to the BRP at the start of the process. To measure successful navigation appears to be more complex than just measuring outcome. These competencies express some direction toward what education for BRPs should entail, as well as pointing toward the future licensing requirements of BRPs.

\section{Implications for the rescue industry}

Several contributions and improved insights for theory building were observed when judging the findings of this exploratory research.

Firstly, the overlapping of activities, especially within the first weeks of the assignment, is highlighted. In particularly complex rescues involving multiple affected parties and network corporate structures, the effect thereof may be intense and require competencies at expert levels. The related skills of prioritising and time management are deemed basic prerequisites. The question arises whether such elements should be deemed relevant as training content for BRPs, or whether they should be assumed to be part of the make-up of future application processes. Selection for the competencies when appointing a BRP is probably the most important decision for boards or directors.

Secondly, preparing the rescue plan appeared to be judged by the subjects as being the unique and main function of the rescue practitioners. It was judged to be a highly important activity $(88 \%)$, not transferable $(67 \%)$, requiring high-level knowledge $(67 \%)$ and tacit skills (79\%). High levels of sense-making competency specifically enhance this ability and, whilst rescue authorities can gain by being more prescriptive about the specific requirements and minimum content to be included in final plans, those BRPs with this competency should be sourced for rescues. To meet with stakeholders was rated as being the second most difficult-todelegate activity, leading to the collaboration competency as core mediator of the competencies in executing the BRP tasks, as is shown in Figure 3.

Thirdly, related to the above, meeting with affected parties was judged to be the second most important function of the rescue practitioners as it was seen as being highly important $(85 \%)$, not transferable $(64 \%)$ and required high-level knowledge (52\%) and tacit skills (59\%). Education should address collaboration techniques specifically. 
Fourthly, the identified competencies require more than knowledge and techniques obtained by attending courses. All four higher-level competencies benefit from experience, despite the limitations of experience suggested by Baron and Ensley (2006:1333), who state that, 'it seems clear that growing experience does not in any way guarantee progress toward exceptional levels of achievement'; and Day (2010:41), who states that learning from experience is thought to be more difficult than any other avenue. This could be a practical problem to be addressed by, for example, instituting apprenticeships.

Fifthly, education institutions could apply the findings by incorporating the higher-order competencies as the basis for their rescue-specific training courses. The CIPC, for example, as the governing body controlling the qualifications of BRPs, could now use the proposed framework to guide both the training and examination of BRPs. The framework should be investigated through further research and could eventually form the basis of the audit system of BRPs as envisaged by authorities.

Finally, competence measurement was not addressed in this article. One thing, however, that became clear during this research, after contemplating the findings and competency framework, is that only an expert or master BRP would be able to judge competence. For that, a competence framework should be developed based on the competencies described above. It would probably require a disaggregation of the higher-order competencies to fundamental competencies in order to allow measurement.

\section{Limitations and further research}

Despite the data being obtained directly from the primary source, namely BRPs, the main limitation of this research is the researcher's potential bias during both the data analysis and interpretation of results phases. Secondly, potential subject bias has also been pointed out and the results should thus serve as guideline dimensions rather than absolute criteria. The proposed education competencies framework is not excluded from this bias either. The results must be evaluated with this in mind, as other interpretations may have been overlooked.

As regards the competency concept, perception of the competencies of the 'double' to whom the instructions were given in the mind of the BRP, could have influenced the subjects when writing the instructions. Consider that giving instruction to a perceived 'competent' may be different from instructing a perceived 'incompetent' double - similar to the underlying principles of 'situational leadership'. This might have affected the detailed levels of the instructions collected during the research.

Future research should seek further validation of the competency framework and expansion to a competence model for evaluation of BRP competencies. Specific techniques applied by BRPs that make them competent executors of the competencies may be of great value to practitioners and educators alike.

As the 'unique' business rescue activity, preparing the rescue plan should become a research focus.

\section{Acknowledgements}

The author would like to extend his thanks to Ms Amanda Lotheringen from CIPC, who made the access to research subjects possible.

\section{Competing interests}

The author declares that he has no financial or personal relationship(s) which may have inappropriately influenced him in writing this article.

\section{References}

Abuel-Ealeh, S., 2009, Review of literature relating to competency frameworks for researchers, Report of the Careers Research and Advisory Centre, Vitae.

Alfalla-Luque, R., Medina-Lopez, C. \& Dey, P.K., 2013, 'Supply chain integration framework using literature review', Production Planning \& Control 24(8-9), 800817. http://dx.doi.org/10.1080/09537287.2012.666870

Allio, R.J., 2013, 'Leaders and leadership - many theories, but what advice is reliable?', Strategy \& Leadership 41(1), 4-14. http://dx.doi. org/10.1108/10878571311290016

ATE judgment, 2012, Case Number 72522/11, in the matter between: Advanced Technologies and Engineering Company (Pty) Ltd (in business rescue) and Aeronautique Technologies, in the High Court of South Africa (North Gauteng High Court).

Baba, V.V. \& HakemZadeh, F., 2012, 'Toward a theory of evidence based decision making', Management Decision 50(5), 832-867. http://dx.doi. org/10.1108/00251741211227546

Baird, S. \& Lorence, M, 2012, 'Predicting success: A doctoral research study', Journal of Corporate Renewal Nov/Dec, 20-23.

Balovich, D., 2002, Chapter 11 confirmation, viewed 12 March 2013, from http:// www.creditworthy.com/3jm/articles/cw42402.html

Baron, R.A. \& Ensley, M.D., 2006, 'Opportunity recognition as the detection of meaningful patterns: evidence from the comparisons of novice and experienced
entrepreneurs', Management Science 52(9), 1331-1344. http://dx.doi. entrepreneurs', Management
org/10.1287/mnsc.1060.0538

Boyatzis, R., 1982, The competent manager: A model for effective performance, Wiley, New York.

Boyd, D.P., 2011, 'Lessons from turnaround leaders', Strategy \& Leadership 39(3), 36-43. http://dx.doi.org/10.1108/10878571111128801

Bradstreet, R., 2010, 'The leak in the Chapter 6 lifeboat: inadequate regulation of business rescue practitioners may adversely affect lenders' willingness and the growth of the economy', South African Mercantile Law Journal 22, 195-213, viewed 13 May 2014, from http://www.companylaw.uct.ac.za/usr/companylaw/ downloads/articles/bradstreet_ch6.pdf

BRPortal, 2012, Second-generation scenarios for business rescue in South Africa, viewed 13 May 2014, from http://www.brportal.co.za/_literature_154313/ Second_Generation_business_rescue_scenarios_October_2012

Bruni, A. \& Gherardi, S., 2001, 'Omega's story: The heterogeneous engineering of a gendered professional self', in M. Dent \& S. Whitehead (eds.), Managing professional identities, knowledge, performativity and 'new' professional, pp. 174-198, Routledge, London.

Campion, M.A., Fink, A.A., Ruggeberg, B.J., Carr, L, Phillips, G.M. \& Odman, R.B., 2011, 'Doing competencies well: Best practices in competency modeling', Personnel Psychology 64(1), 225-262. http://dx.doi.org/10.1111/j.1744-6570.2010.01207.x

Corbin, J. \& Strauss, A., 1990, 'Grounded theory research: Procedures, canons and evaluative criteria', Qualitative Sociology 13(1), 3-21. http://dx.doi.org/10.1007/ BF00988593

Day, D.V., 2010, 'The difficulties of learning from experience and the need for deliberate practice', Industrial and Organizational Psychology 3(1), 41-44. http:// dx.doi.org/10.1111/j.1754-9434.2009.01195.x

Dreyfus, S.E. \& Dreyfus, H.L., 1980, A five-stage model of mental activities involved in directed skills acquisition, Operations Research Center, University of California, Berkeley.

Dulewicz, V., 1999, 'Personal competencies, personality and responsibility of middle managers', Competency 1(3), 20-29.

Du Preez, W., 2012, 'The status of post commencement finance for business rescue in South Africa', unpublished BBA thesis, GIBS, University of Pretoria. 
Furnam, A. \& Mansi, A., 2011, 'Correlates of self-rated business competencies', International Journal of Business and Management 6(9), 3-13.

Gherardi, S., 1995, 'When will he say: "Today the plates are soft"? The management of ambiguity and situated decision-making', Studies in Cultures, Organizations and Societies 1(1), 9-27. http://dx.doi.org/10.1080/10245289508523443

Gottfredson, M., Schaubert, S. \& Hirzel, A., 2008, 'Leading fast turnarounds', Business Strategy Review 19(3), 28-33. http://dx.doi.org/10.1111/j.1467 8616.2008.00549.x

Henning, E. 2011. Finding your way in qualitative research, 8th edn., Van Schaik Publishers, Pretoria.

Jacobs, L.M., 2012, 'Die nuwe ondernemingsreddingpraktisyn: Geneesheer of begrafnisondernemer?' $n$ Ondersoek na die kwalifikasies van die reddingspraktisyn [The new business rescue practitioner: surgeon or undertaker? An investigation into the qualifications of the rescue practitioner]', Litnet Academic 9(2), 202 228, viewed 10 September 2012, from http://www.litnet.co.za/Article/dienuwe-ondernemingsreddingspraktisyn-geneesheer-of-begrafnisondernemer-nondersoek-na

Kahneman, D., 2011, Thinking, fast and slow, Farrar, Straus and Giroux, New York.

Kierulff, H. \& Petersen, H.L., 2009, 'Finance is everything: Advice from turnaround managers', Journal of Business Strategy 30(6), 44-51. http://dx.doi. org/10.1108/02756660911003112

Klein, G., Moon, B. \& Hoffman, R.R., 2006, 'Making sense of sensemaking 1 Alternative perspectives', IEEE Intelligent Systems 21(4), 70-73. http://dx.doi. org/10.1109/MIS.2006.75

Klein, J., Gee, D. \& Jones, H., 1998, 'Analysing clusters of skills in R\&D - core competencies, metaphors, visualization, and the role of IT', R\&D Management 28(1), 37-42. http://dx.doi.org/10.1111/1467-9310.00079

Leinwand, P. \& Mainardi, C., 2013, 'Beyond functions', Strategy+Business Magazine 70, 1-4.

Lotheringen, A., 2014, 'Role and responsibilities of the CIPC in business rescue', presentation at the Business Rescue decision-making course, University of Pretoria, 20 February.

McCann, P., 2009, Turnarounds: Brains, guts \& stamina, Trafford Publishing, Bloomington, IN.

Midanek, D.H., 2002, 'How to pick the right turnaround manager', Journal of Private Equity 5(4), 21-24. http://dx.doi.org/10.3905/jpe.2002.320019

Mindlin, P., 2013, 'Comparative analysis of Chapter 6 of the South African Companies Act, No. 71 of 2008 (Business Rescue Proceeding)', presentation to the Company Law Symposium, organised by The South Africa Department of Trade and Industry and The Specialist Committee on Company Law, March.

Mirabile, R.J., 1997, 'Everything you wanted to know about competency modeling', Training \& Development 51(8), 73-77.

Nikolaou, I., Gouras, A., Vakola, M. \& Bourantas, D., 2007, 'Selecting change agents: Exploring traits and skills in a simulated environment', Journal of Change Management 7(3-4), 291-313. http://dx.doi.org/10.1080/14697010701779173

Nicolini, D., 2006, 'The work to make telemedicine work: A social and articulative view', Social Science \& Medicine 62(11), 2754-2767. http://dx.doi.org/10.1016/j. socscimed.2005.11.001

Nicolini, D., 2007, 'Stretching out and expanding work practices in time and space: The case of telemedicine', Human Relations 60(6), 889-920. http://dx.doi. org/10.1177/0018726707080080
Nicolini, D., 2009, 'Articulating practice through the interview to the double', Management Learning 40(2), 195-212. http://dx.doi.org/10.1177/1350507608101230

Parliament of the United Kingdom, 2006, Companies Act 2006, viewed 29 May 2014 from www.legislation.gov.uk/ukpga/2006/46/contents

Pretorius, M., 2008, 'When Porter's generic strategies are not enough: Complementary strategies for turnaround situations', Journal of Business Strategy 29(6), 19-28.

Pretorius, M., 2009, 'Defining business decline, failure and turnaround: A content analysis', South African Journal of Entrepreneurship and Small Business Management 2(1), 1-16.

Pretorius, M., 2013, 'Tasks and activities of the business rescue practitioner: A strategy as practice approach', South African Business Review 17(3), 1-26.

Pretorius, M. \& Du Preez, W., 2013, 'Constraints on decision making regarding post-commencement finance in business rescue', South African Journal of Entrepreneurship and Small Business Management 6, 168-191.

Pretorius, M. \& Holtzhauzen, G.T.D., 2008, 'Critical variables of venture turnarounds: A liabilities approach', Southern African Business Review 12(2), 87-107.

Pretorius, M. \& Holtzhauzen, G.T.D., 2013, 'Business rescue decision making through verifier determinants - ask the specialists', South African Journal of Economic and Management Sciences 16(4), 468-485.

Pretorius, M. \& Rosslyn-Smith, W., 2014, 'International guidelines for business rescue plans', South African Business Review, in press, accepted for publication 2014 http://dx.doi.org/10.1108/02756660810917200

Scherrer, P.S., 2003 'Management turnarounds: Diagnosing business ailments', Corporate Governance 3(4), 52-62. http://dx.doi.org/10.1108/14720700310497122

Schoemaker, P.J.H., Krupp, S. \& Howland, S., 2013, 'Strategic leadership: The essential skills', Harvard Business Review January-February, 2-5.

Shook, C.L., Priem, R.L. \& McGee, J.E., 2003, 'Venture creation and the enterprising individual: A review and synthesis', Journal of Management 29(3), 379-399. http://dx.doi.org/10.1016/S0149-2063(03)00016-3

Sonteya, T. \& Seymour, L., 2012, 'Towards an understanding of the business process analyst: An analysis of competencies', Journal of Information Technology Education: Research 11, 43-63.

South Africa, 2008, Companies Act 71 of 2008, Government Gazette No. 32121 Volume 421, Government Printer, Pretoria.

Teodorescu, T., 2006, 'Competence versus competency: What is the difference?', Performance Improvement 45(10), 27-30. http://dx.doi.org/10.1002/ pfi.4930451027

TMA (Turnaround Management Association: Body of Knowledge), 2009, Certified Turnaround Professional - Management module, TMA, Chicago, IL.

Trahms, C.A., Ndofor, H.A. \& Sirmon, D.G., 2013, 'Organizational decline and turnaround: A review and agenda for future research', Journal of Management 39(5), 1227-1307. http://dx.doi.org/10.1177/0149206312471390

Van der Linde, K., 2008, 'Priority issues in post-commencement financing - a view from South Africa', in Wessels and Omar (eds.), The Intersection of Insolvency and Company Laws - Papers from the INSOL Europe Academic Forum Annual conference Barcelona, Spain, 1-2 October 2008, INSOL Europe, Nottingham.

Yin, R.K., 2003, Case study research: Design and methods (Applied social research methods), 3rd edn., Applied social research methods Series Volume 5, Sage Publications, London. 